\title{
Interannual variability in spring bloom timing and magnitude in the Rhode River, Maryland, USA: observations and modeling
}

\author{
C. L. Gallegos*, T. E. Jordan, D. L. Correll \\ Smithsonian Environmental Research Center, PO Box 28, Edgewater, Maryland 21037, USA
}

\begin{abstract}
The long-term average seasonal distribution of chlorophyll concentration in a central reach of the Rhode River estuary (Maryland, USA) has a peak in the spring of about $90 \mathrm{mg} \mathrm{m}^{-3}$. Here we examine interannual variability in chlorophyll and nutrient concentrations in recent years. Years are classified as having an average bloom, extraordinary bloom, or no bloom, and patterns of nutrient concentration are described for each category. To determine processes associated with the different categories of behavior, we performed a generalized sensitivity analysis of a model of nutrient-limited phytoplankton net growth which was previously shown to simulate the chlorophyll concentration and the observed pattern of shift from $\mathrm{P}$ to $\mathrm{N}$ limitation in an average year. Model parameters controlling the delivery of $\mathrm{N}$ and $\mathrm{P}$ by the environment and the biological utilization of nutrients by the phytoplankton were drawn from random distributions based on literature reports or, where available, data from the Rhode River. Model output for each parameter set was classified according to which, if any, of the classes of bloom it exhibited. Environmental processes most responsible for the variability in predicted spring blooms were the rate of phosphorus release from the sediment, the timing of nitrate depletion at the seaward boundary, and the maximal nitrate concentration at the boundary. Simulation of bloom failure was most strongly associated with low rates of phosphorus release from the sediment. Phytoplankton physiological parameters most responsible for variability in categories of behavior were the nitrogen:chlorophyll conversion factor, and the maximum internal storage capacity for phosphorus. Blooms of extraordinary magnitude were associated with low nitrogen:chlorophyll ratios and high storage capacity for phosphorus. Results help identify key processes and parameters in need of further understanding as well as possible points for managerial intervention.
\end{abstract}

KEY WORDS: Phytoplankton · Spring bloom · Estuarine $\cdot$ Nitrogen $\cdot$ Phosphorus

\section{INTRODUCTION}

In many marine systems, the spring bloom represents the major seasonal net input of carbon into the food web (Legendre 1990). Blooms of phytoplankton are also important determinants of water quality, especially in estuaries. For example, in Chesapeake Bay (USA) much of the spring diatom bloom settles and decomposes in waters below the pycnocline, thereby fueling summertime oxygen depletion (Malone et al. $1988,1996)$. Additionally, spring bloom levels of phyto-

•E-mail: gallegos@serc.si.edu plankton chlorophyll in Chesapeake Bay reduce underwater light below the requirements for survival of submerged aquatic vegetation (Dennison et al. 1993). Understanding the factors that control the timing and magnitude of the spring phytoplankton bloom in a system is, therefore, important for determining both the limits to secondary production and the causes of water quality problems.

The factors regulating bloom development fall broadly into constraints related to conservation of mass or to population dynamics. Production of new phytoplankton biomass requires that all of the nutrients needed to make new cells be available in the water. For biomass to accumulate the growth rate of phyto- 
plankton must also temporarily exceed the sum of all loss rates. Growth rate is known to depend on light intensity, temperature, and nutrient stores (Parsons et al. 1984). Loss processes include sinking, grazing, advection, and endogenous cell death. Any change in conditions that shifts the balance between growth rate and loss rates toward positive net growth for some component of the phytoplankton community can produce phytoplankton blooms (Legendre 1990).

In nutrient-limited systems, allochthonous inputs of the limiting nutrient may enhance net growth rates of the resident phytoplankton by providing the material for making new cells. Identification of the limiting nutrient has, therefore, been the subject of numerous studies (Smith 1984, D'Elia et al. 1986, Nixon 1987. Paasche \& Erga 1988, Pennock \& Sharp 1994). For some estuaries it has been recognized that the limiting nutrient can shift seasonally from $\mathrm{P}$ (or $\mathrm{Si}$ ) at the time of the spring bloom, to $\mathrm{N}$ in summer and autumn (Fisher et al. 1992), whereas in others $N$ (Rudek et al. 1991) or, in some brackish waters, P (Sakshaug \& Olsen 1986) is the principal limiting nutrient year round.

Previous studies of the Rhode River (Maryland, USA), a tributary embayment on the western shore of Chesapeake Bay, have shown that phytoplankton blooms there are related to episodic input of $\mathrm{N}$ but not P. Analysis by Jordan et al. (1991b) of both seasonal and short term responses indicated that chlorophyll concentrations in the spring were controlled by nitrate inputs from the Susquehanna River, the principal freshwater source to the upper Bay. Summer chlorophyll correlated with Susquehanna flow during the previous spring, indicating control by inorganic $\mathrm{N}$ regenerated from organic matter produced in the spring. This appears to differ from the main stem of Chesapeake Bay where Fisher et al. (1992) concluded that, because the Susquehanna River is a source of excess $N$, the accumulation of algal biomass is limited by $\mathrm{P}$ and $\mathrm{Si}$ following the spring runoff maximum, with $\mathrm{N}$ limiting in summer.

The objectives of this paper are to determine how the processes that supply $\mathrm{N}$ and $\mathrm{P}$ in a subestuary interact with the biology of phytoplankton to govern the magnitude of the spring phytoplankton bloom in the Rhode River. We examine recent data to determine the extent of interannual variability in the spring bloom timing and magnitude, and in the concurrent concentrations of $\mathrm{N}$ and $\mathrm{P}$. The role of hard-to-observe environmental and biological processes in causing the variability is investigated using a previously developed (Gallegos \& Jordan unpubl.) model of light-, temperature-, and nutrient-limited phytoplankton net growth in a subestuary. We perform a generalized sensitivity analysis of the model (Hornberger \& Spear 1981) by varying the parameters that govern the allochthonous inputs of nutrients and their utilization by phytoplankton over the range likely to be encountered in the system. Statistical analysis of the parameters and their predicted bloom characteristics is used to determine which combinations of parameters (and by inference the underlying processes) are most important in simulating the observed degree of variability.

\section{METHODS}

Study site. The Rhode River $\left(38^{\circ} 51^{\prime} \mathrm{N}, 75^{\circ} 36^{\prime} \mathrm{W}\right)$ is one of several tributary embayments or subestuaries on the western shore mesohaline region of Chesapeake Bay in Maryland, USA. It is 550 ha in area. Depth at MLW (mean low water) varies from $4 \mathrm{~m}$ at the mouth to $<1 \mathrm{~m}$ in the upper subtidal regions. Land composition in the 2300 ha watershed of Muddy Creek, the principal freshwater source to the upper subestuary, is mostly forest and farms (Jordan et al. 1991a).

Sampling and water quality analyses. For sampling purposes we divided the estuary into 8 segments (see Fig. 1 in Jordan et al. 1991a) with lengths greater than 1 tidal excursion and boundaries corresponding to natural constrictions in the morphometry. Segment areas, volumes, and areas of their surrounding watersheds are given by Jordan et al. (1991a). Attention here is focused on segment 4 , which is sufficiently removed from the mainstem Chesapeake Bay to reflect local biological processes, but which is only rarely flushed by the largest of local storms.

Spatially integrated samples for nutrient concentrations and, prior to 1989, for chlorophyll were collected at high water by running a small boat along the axis of a segment while pumping from a depth of $0.1 \mathrm{~m}$ into a carboy using a battery operated peristaltic pump. Sampling was conducted approximately fortnightly from March through November. Methods for nutrient analyses have remained constant over the period reported here and are described fully by Jordan et al. (1991a, b). Briefly, samples to be analyzed for dissolved nutrients were filtered through prewashed $0.45 \mu \mathrm{m}$ Millipore filters. Standard colorimetric techniques (Strickland \& Parsons 1972, APHA 1989) were used to measure concentrations of dissolved inorganic phosphate (DIP) and $\mathrm{NO}_{3}$.

Prior to 1989 chlorophyll was determined in subsamples of the water collected for nutrient analyses. Particulate matter for chlorophyll analyses was collected on glass fiber filters (Schleicher and Schuell) and extracted with a mixture of acetone and DMSO (Shoaf \& Lium 1976). Absorbances of extracts were read spectrophotometrically and concentrations were calculated 

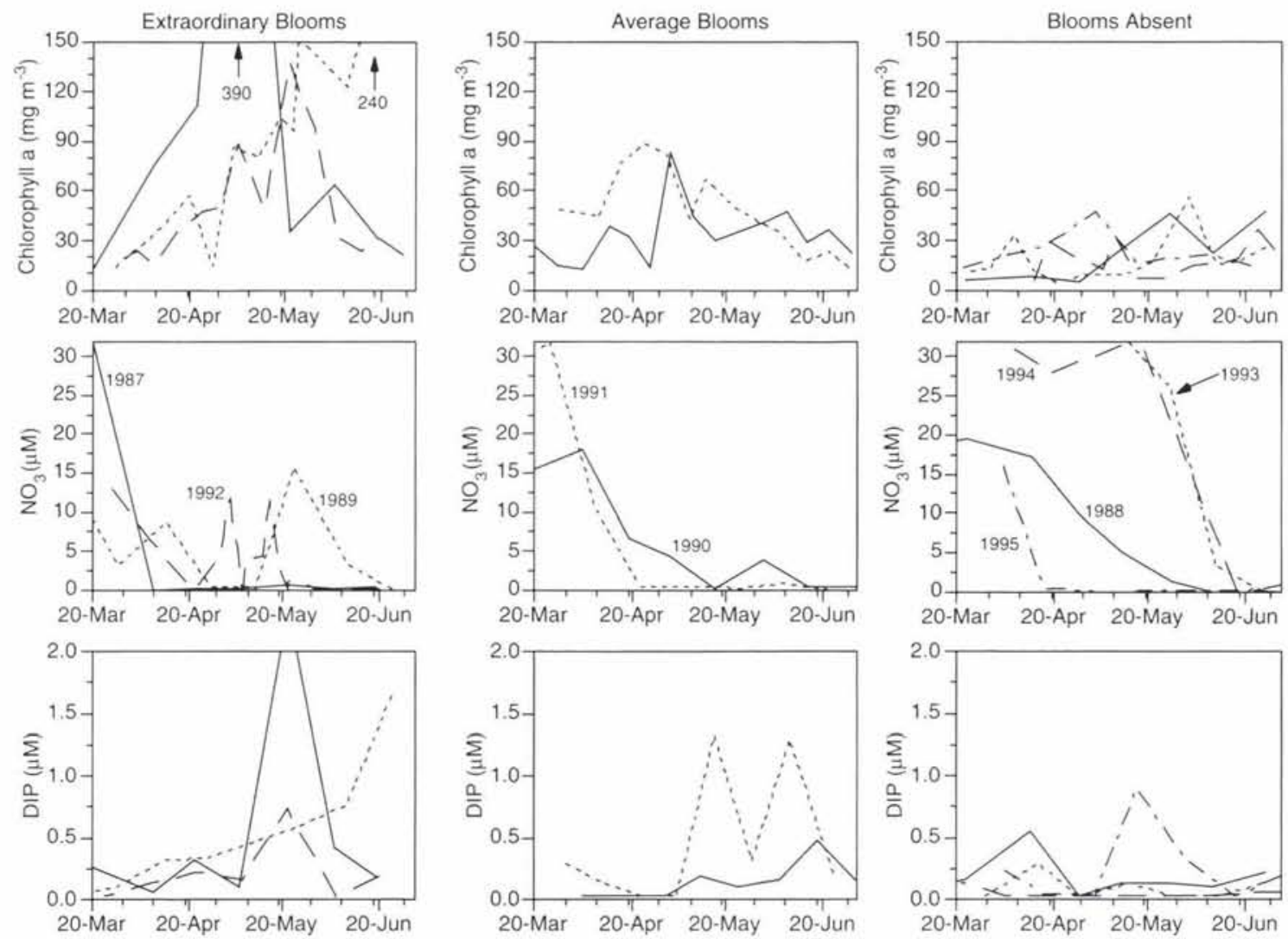

Fig. 1. Concentrations of phytoplankton chlorophyll a (top panels), nitrate (middle panels) and dissolved inorganic phosphorus (DIP, lower panels) in the Rhode River (Maryland, USA) for the spring periods of 1988 to 1995 . $\mathrm{NO}_{3}$ and DIP axes are scaled by the Redfield ratio (16:1) so that the nutrient most likely to be limiting phytoplankton accumulation at a particular time is the one falling lower on the graph. Years are grouped by whether the spring bloom was of extraordinary magnitude, average magnitude, or absent. Offscale peak $\mathrm{NO}_{3}$ concentrations in the 2 non-bloom years, 1993 and 1994, were 52 and $40 \mu \mathrm{M}$, respectively

by equations of Jeffrey \& Humphrey (1975). Separate sampling at weekly intervals for phytoplankton chlorophyll and population dynamics commenced in 1989. Particulate matter was collected on Whatman GF/F filters, extracted overnight at $4^{\circ} \mathrm{C}$ and analyzed spectrophotometrically as above. Samples in 1989 were collected from the Secchi depth, but due to vertical nonuniformity during the blooms in that year, we began collecting vertically integrated samples in subsequent years.

\section{RESULTS-FIELD OBSERVATIONS}

\section{Interannual variability in spring blooms}

Maximal springtime chlorophyll values in segment 4 varied widely from $30 \mathrm{mg} \mathrm{m}^{-3}$ in 1994 to $390 \mathrm{mg} \mathrm{m}^{-3}$ in 1987 (Fig. 1). To facilitate presentation we classified the years having peak chlorophylls in segment 4 between 70 and $110 \mathrm{mg} \mathrm{m}^{-3}$ as 'average bloom' (i.e. similar to the long-term average; Jordan et al. 1991a), those having peak chlorophylls $>120 \mathrm{mg} \mathrm{m}^{-3}$ as 'extraordinary blooms', and years with peak chlorophylls $<60 \mathrm{mg} \mathrm{m}^{-3}$ as 'bloom absent'. Though $60 \mathrm{mg} \mathrm{m}^{-3}$ chlorophyll is high for most systems, it is only slightly higher than the average summer 'background' concentration from 1978 to 1989 (Jordan et al. 1991a). We use these classifications later in the sensitivity analysis of model simulations. By these criteria, 2 years (1990 and 1991) resembled the average curve for segment 4 (Jordan et al. 1991a), in 3 years (1987, 1989, and 1992) there were extraordinary blooms, and 4 years $(1988,1993,1994$ and 1995) lacked blooms (Fig. 1).

Timing of peak chlorophyll in years having blooms varied from 25 April in 1991 to 19 June in 1989. The 2 blooms occurring latest in spring (the 'extraordinary' blooms of 1989 and 1992) each had chlorophyll concentrations of about $90 \mathrm{mg} \mathrm{m}^{-3}$ (i.e. near the levels of average blooms) in early May, after which further increases resulted in extraordinary blooms (Fig. 1). 
That is, extraordinary blooms in those years occurred as events subsequent to blooms of average magnitude.

\section{Nutrient concentrations}

Concentrations of $\mathrm{NO}_{3}$ and DIP varied widely during the spring within and among years with blooms of different magnitudes (Fig. 1). In years with blooms, $\mathrm{NO}_{3}$ was depleted by 30 April, after which DIP began to accumulate in excess (Fig. 1). A return of $\mathrm{NO}_{3}$ due to high flow of the Susquehanna River after a period of $\mathrm{NO}_{3}$ depletion characterized years having extraordinary blooms, as described for 1989 by Gallegos et al. (1992). Similarly, an extraordinary bloom occurred in 1992 following an injection of $\mathrm{NO}_{3}$ by high flow (Fig. 1). In 1987 fortnightly sampling apparently missed the $\mathrm{NO}_{3}$ injection that stimulated the extraordinary bloom. However, unpublished conductivity records monitored at the Smithsonian pier adjacent to segment 4 indicate the arrival of a freshet on 10 April 1987, $11 \mathrm{~d}$ prior to the nearest water quality sampling.

In 3 of the years without blooms $\mathrm{NO}_{3}$ was more persistent in the system than in years having blooms (Fig. 1). The springs of 1993 and 1994 were unusually wet, and $\mathrm{NO}_{3}$ concentrations were higher than normal and persisted into mid-June. In 1988 the initial concentration was not unusually high but the rate of depletion was low and $\mathrm{NO}_{3}$ remained detectable and in excess of $16 \times$ DIP to late May. In 1995, both $\mathrm{NO}_{3}$ and DIP were low, but $\mathrm{NO}_{3}$ appeared to be in excess until mid-April (Fig. 1).

The persistence of $\mathrm{NO}_{3}$ in years lacking blooms appeared to conflict with previous analyses (Jordan et al. 1991b, Gallegos et al. 1992) which pointed to the importance of $\mathrm{NO}_{3}$ inputs in triggering phytoplankton blooms in the Rhode River in spring. To resolve this issue and further explore the relative importance in the factors controlling bloom formation, we performed a sensitivity analysis using a previously developed model (Gallegos \& Jordan unpubl.) of nutrient-limited phytoplankton net growth in the Rhode River. The objective of the analysis is to improve our understanding of the conditions that produce different phytoplankton dynamics in spring.

\section{MODEL DESCRIPTION}

\section{Model structure}

Despite ample measurements of phytoplankton chlorophyll and nutrients in the Rhode River, many of the important processes or physiological parameters thought to govern timing and magnitude of the spring bloom (e.g. nutrient half-saturation coefficients, maximal specific uptake rates, nutrient:chlorophyll conversion ratios) have not been measured in this system. Some processes, such as the rate of net DIP production, have been measured but show a high degree of unsystematic variability (Jordan et al. 1991a). Other quantities, such as nutrients stored internally by phytoplankton, have no routine method of measurement in natural populations. We therefore constructed a model and performed a sensitivity analysis to see which of these and other processes are most important in determining the degree of variability observed in the system.

Structure and rationale of the model and calibration to a typical year are described fully elsewhere (Gallegos \& Jordan unpubl.). Here we describe the broad structure of the model, emphasizing processes shown to be important in generating the variety of behavior observed. We represent the subestuary as a series of 3 well-mixed compartments, assumed to be homogenous, and which exchange contents with neighboring segments. Numbering of the segments was chosen to conform with previous models of the Rhode River. Attention here is restricted to segments denoted 3 through 5 by Jordan et al. (1991a) because conditions seaward of segment 3 diverge only slightly from the shoulders of the mainstem Chesapeake Bay (considered here to be the seaward boundary), and upstream of segment 5 the volume of water is small and the segments are sometimes flushed by high flow events that may obscure seasonal patterns.

The model tracks concentrations of nitrogen and phosphorus as they exchange amongst 3 pools within each segment, $i$, and between neighboring segments or across the seaward boundary. The formulation of nutrient uptake and phytoplankton growth is very similar to that of Riegman \& Mur (1984). Dissolved, available nitrogen and phosphorus, $N_{i}$ and $P_{l}$, are taken up by phytoplankton first into internal storage pools, $Q_{i}^{\mathrm{N}}$ and $Q_{i}^{p}$, from which growth of new producing biomass, $B_{i}^{N}$, and $B_{i}^{P}$, takes place. The production of $B^{N}$ and $B^{p}$, but not the uptake into $Q^{N}$ and $Q^{P}$, is regulated to maintain stoichiometric balance, such that $B^{N}: B^{p}=\theta_{N} p$, where $\theta_{N}$ is the N:P ratio of the producing biomass (definitions of variables and parameters are given in Table 1). The treatment, therefore, allows for 'luxury consumption' of the non-limiting nutrient into the internal storage pools. The maximum amount of internally stored $N$ and $P$, relative to $B^{N}$ and $B^{p}$, is governed by dimensionless parameters, $Q_{N}{ }^{\max }$ and $Q_{p}{ }^{\max }$, respectively. Chlorophyll concentration, $C_{j}$, in each segment is assumed to be related stoichiometrically to $B_{j}^{\mathrm{N}}$ by a yield coefficient, $\theta_{\text {chl at }}$ that is, $C_{i}=B_{i}^{N} / \theta_{\text {chl a }}$.

Mass balance equations for concentrations in each segment are of the form 
Table 1. Definition of symbols used in model of nutrients and chlorophyll in the Rhode River, Maryland, USA

\begin{tabular}{|c|c|c|}
\hline $\begin{array}{l}i, j \\
X\end{array}$ & $\begin{array}{l}\text { No units } \\
\mu \mathrm{M} \text { or } \mathrm{mg} \mathrm{m}^{-3}\end{array}$ & $\begin{array}{l}\text { Indexes denoting segment numbers; } 0 \text { denotes boundary } \\
\text { Symbol to designate concentration of any state variable in generic mass balance equation for } \\
\text { mixing and uptake or growth }\end{array}$ \\
\hline$S_{i}^{\mathrm{X}}$ & Concentration $\mathrm{d}^{-1}$ & Net rate of consumption or production of constituent $\mathrm{X}$ in segment $i$ \\
\hline$q_{2,1}$ & $d^{-1}$ & Exchange rate between segments $i$ and $j$ \\
\hline$N_{i}$ & $\mu \mathrm{M}$ & Concentration of dissolved inorganic $\mathrm{N}$ in segment $i$ \\
\hline$P_{1}$ & $\mu \mathrm{M}$ & Concentration of dissolved inorganic $\mathrm{P}$ in segment $i$ \\
\hline$C_{i}$ & $\mathrm{mg} \mathrm{m}^{-3}$ & Concentration of phỵtoplankton chlorophyll $a$ in segment $i$ \\
\hline$B_{i}^{N}$ & $\mu \mathrm{M}$ & Concentration of $\mathrm{N}$ in producing biomass of phytoplankton \\
\hline$B_{i}^{p}$ & $\mu \mathrm{M}$ & Concentration of $\mathrm{P}$ in producing biomass of phytoplankton \\
\hline$Q_{i}^{N}$ & $\mu \mathrm{M}$ & Concentration of internally stored $\mathrm{N}$ in phytoplankton \\
\hline$Q_{1}^{p}$ & $\mu \mathrm{M}$ & Concentration of internally stored $\mathrm{P}$ in phytoplankton \\
\hline$Q_{N}^{\max }$ & No units & Factor multiplying $B^{N}$ that determines the maximal internally stored $\mathrm{N}$ \\
\hline $\mathrm{Q}_{\mathrm{p}}^{\max }$ & No units & Factor multiplying $B^{p}$ that determines the maximal internally stored $\mathrm{P}$ \\
\hline$f_{0}^{\mathrm{QN}}$ & No units & Fraction of $Q_{N}{ }^{\max }$ stored internally by phytoplankton at the seaward boundary \\
\hline$f_{0}{ }^{Q P}$ & No units & Fraction of $Q_{p}{ }^{\max }$ stored internally by phytoplankton at the seaward boundary \\
\hline$N_{0} \max$ & $\mu \mathrm{M}$ & Maximal concentration of $N$ at seaward boundary \\
\hline$t_{\mathrm{mi}}$ & No units & Day of year at which $N_{0}=N_{0}^{\max } / 2$ \\
\hline$t_{\mathrm{d}}$ & No units & Parameter controlling rate of decline of boundary $N$ \\
\hline$K_{\mathrm{s}}{ }^{\mathrm{N}}$ & $\mu \mathrm{M}$ & Half-saturation concentration for $\mathrm{N}$ uptake \\
\hline$K_{\mathrm{S}}^{\mathrm{p}}$ & $\mu \mathrm{M}$ & Half-saturation concentration for $P$ uptake \\
\hline$K_{\mathrm{Q}}{ }^{\mathrm{N}}$ & No units & Relative (to $B^{N}$ ) half-saturation concentration of $Q^{N}$ for growth \\
\hline$K_{Q}^{p}$ & No units & Relative (to $B^{p}$ ) half-saturation concentration of $Q^{p}$ for growth \\
\hline$T$ & ${ }^{\circ} \mathrm{C}$ & Water temperature \\
\hline$T_{\text {thr }}$ & ${ }^{\circ} \mathrm{C}$ & Threshold temperature for onset of $P$ release by sediments \\
\hline$r_{i}^{\mathrm{P}}$ & $\mathrm{mmol} \mathrm{m} \mathrm{m}^{-2}$ & Areal rate of $\mathrm{P}$ release by sediments in segment $i$ \\
\hline$r_{r}^{p}$ & $\mathrm{mmol} \mathrm{m} \mathrm{d}^{-1}$ & Areal rate of $\mathrm{P}$ release by sediments at reference temperature of $30^{\circ} \mathrm{C}$ \\
\hline$z_{i}$ & $\mathrm{~m}$ & Depth of segment $i$ \\
\hline$\rho_{N}^{\max }$ & $\mathrm{d}^{-1}$ & Maximal biomass-specific uptake rate of $\mathrm{N}$ \\
\hline$\rho_{p}^{\max }$ & $\mathrm{d}^{-1}$ & Maximal biomass-specific uptake rate of $\mathrm{P}$ \\
\hline$\theta_{N P}$ & No units & Molar ratio of $\mathrm{N}$ to $\mathrm{P}$ in the producing biomass of phytoplankton \\
\hline$\theta_{\text {chl } a}$ & $\mu \mathrm{g} \mu \mathrm{M}^{-1}$ & Ratio of phytoplankton biomass $\mathrm{N}$ to chlorophyll \\
\hline$\theta_{N: p^{\text {sed }}}$ & No units & Molar ratio of rate of DIN to $\mathrm{P}$ release by sediments \\
\hline
\end{tabular}

$$
\frac{\mathrm{d} X_{i}}{\mathrm{~d} t}=q_{i-1, i}\left(X_{i-1}-X_{i}\right)+q_{i, i+1}\left(X_{i+1}-X_{i}\right)+\sum S_{i}^{\mathrm{X}}
$$

where $X$ is the concentration of any variable (i.e. $N, P$, $Q^{N}, Q^{p}, B^{N}, B^{p}$, or $C$ ) in segment $i, q\left(\mathrm{~d}^{-1}\right)$ is the mixing coefficient between adjacent segments, and $\Sigma S_{t}^{\mathrm{X}}$ (concentration units $\mathrm{d}^{-1}$ ) is the sum of all sources and losses of constituent $\mathrm{X}$ in segment $i$. For segment 3, concentrations of constituents in the seaward direction are the boundary conditions denoted $N_{0}, P_{0}, Q_{0}{ }^{\mathrm{N}}, Q_{0}{ }^{\mathrm{P}}, B_{0}{ }^{\mathrm{N}}, B_{0}{ }^{\mathrm{P}}$, and $C_{0}$. Inputs from the local watershed and exchange with upper subestuary segments 6 and above (see Jor dan et al. 1991a) are not considered in this analysis. Nutrient inputs from the local watershed result in short-lived, localized phytoplankton blooms, but exchange with the main stem produces blooms of greater magnitude and spatial extent (Gallegos et al. 1992).

Phytoplankton uptake of dissolved nutrients represents sources of $Q^{N}$ and $Q^{P}$, and sinks for $N$ and $P$. Sim- ilarly, growth of new phytoplankton biomass represents sources of $B^{N}$ and $B^{P}$ and sinks for $Q^{N}$ and $Q^{P}$. The dissolved nutrient constituents, $N$ and $P$, have source terms due to release from the bottom sediments. Jordan et al. (1991a) calculated net rates of DIP production by the upper Rhode River subestuary, equivalent in this model to the difference between release from the sediment and uptake by phytoplankton. Rates of DIP production were highly variable from week to week, ranging from -0.4 to $0.6 \mathrm{mmol} \mathrm{m}^{-2}$ $\mathrm{d}^{-1}$ (Jordan et al. 1991a). Median rates were about $0.2 \mathrm{mmol} \mathrm{m}^{-2} \mathrm{~d}^{-1}$ in late summer and about 0 in early spring. Accordingly, we modeled $\mathrm{P}$ release from the sediments, $r_{i}^{\mathrm{P}}\left(\mathrm{mmol} \mathrm{m}^{-2} \mathrm{~d}^{-1}\right)$, as a function of temperature, $T$, for each segment.

$$
\begin{array}{ll}
r_{i}^{\mathrm{P}}=\frac{r_{f}^{\mathrm{P}}\left\{\exp [0.069 \cdot(T-30)]-\exp \left[0.069 \cdot\left(T_{\text {tht }}-T\right) \mid\right]\right.}{z_{i}\left[1-\exp \left[0.069 \cdot\left(T_{\text {thr }}-30\right)\right] \mid\right.} & \left(T \geq T_{\text {thr }}\right)(2 \mathrm{a}) \\
r_{i}^{\mathrm{p}}=0 & \left(T<T_{\text {thr }}\right)(2 \mathrm{~b})
\end{array}
$$

where $r_{r}^{\mathrm{P}}\left(\mathrm{mmol} \mathrm{m}^{-2} \mathrm{~d}^{-1}\right)$ is the areal rate of sediment $\mathrm{P}$ 
release occurring at a reference temperature of $30^{\circ} \mathrm{C}$, $z_{i}(\mathrm{~m})$ is the depth of segment $i$, and $T_{\mathrm{thr}}$ is a threshold temperature for $\mathrm{P}$ release. The constant 0.069 implies a $\mathrm{Q}_{10}$ of 2 ; a threshold temperature of about $7^{\circ} \mathrm{C}$ keeps rates near 0 prior to about early April, which is consistent with patterns of net DIP production found by Jordan et al. (1991a) (see Fig. 7 in Jordan et al. 1991a). Release of $\mathrm{N}$ from the sediment is modeled by an identical expression multiplied by a factor representing the $\mathrm{N}: \mathrm{P}$ ratio of sediment release, $\theta_{\mathrm{N}: \mathrm{p}^{\text {sed }}}$. The concentrations of $\mathrm{N}$ and $\mathrm{P}$ in the sediments are not modeled explicitly.

\section{Phyৃtoplankton physiological parameters}

Equations governing the net growth of phytoplankton are given elsewhere (Gallegos \& Jordan unpubl.). Briefly, the uptake of nutrient from dissolved to internally stored $\mathrm{N}$ and $\mathrm{P}$ was modeled by MichaelisMenten kinetics with half-saturation coefficients $K_{\mathrm{S}}{ }^{\mathrm{N}}$ and $K_{\mathrm{S}}{ }^{\mathrm{p}}$, and temperature-dependent, maximal biomass-specific uptake rates $\rho_{N}{ }^{\max }$ and $\rho_{p}{ }^{\max }$, respectively. Growth of new biomass, $B^{N}$ and $B^{P}$, was modeled as first-order transfer from $Q^{N}$ and $Q^{P}$, respectively, with a specific rate given by the product of a maximal nutrient-sufficient specific rate (a function of irradiance and temperature), and a Monod nutrient-limitation term based on the internal nutrient in shortest supply. The internal nutrient in shortest supply relative to growth demands was determined by concentrations of $Q^{\mathrm{N}}$ and $Q^{\mathrm{P}}$, and dimensionless parameters $K_{\mathrm{Q}}{ }^{\mathrm{N}}$ and $K_{\mathrm{Q}}{ }^{\mathrm{P}}$ which multiply $B^{\mathrm{N}}$ and $B^{\mathrm{P}}$ respectively to determine the amount of internally stored nutrient required to saturate growth rate; that is, the nutrient limitation term is given by $\min \left[Q^{\mathrm{N}} /\left(Q^{\mathrm{N}}+\right.\right.$ $\left.\left.K_{\mathrm{Q}}{ }^{\mathrm{N}} B^{\mathrm{N}}\right), Q^{\mathrm{P}} /\left(Q^{\mathrm{P}}+K_{\mathrm{Q}}^{\mathrm{P}} B^{\mathrm{P}}\right)\right]$.

To reduce the number of free parameters in the sensitivity analysis (see below) we made some simplifying assumptions about the relationships amongst certain parameters. We set $K_{\mathrm{S}}{ }^{\mathrm{p}}=K_{\mathrm{S}}{ }^{\mathrm{N}} / \theta_{\mathrm{N}} \mathrm{p}$, and $\rho_{\mathrm{p}}{ }^{\max }=\rho_{\mathrm{N}}{ }^{\max }$. We used a fixed value of $3 \mathrm{~d}^{-1}$ at $20^{\circ} \mathrm{C}$ and a $Q_{10}$ of 2 for both $\rho_{N}{ }^{\max }$ and $\rho_{p}{ }^{\max }$. Similarly, we used a fixed relationship to describe the dependence of maximal nutrient-saturated growth rate on temperature and irradiance that was an upper bound of growth rates measured by dilution experiments reported elsewhere (Gallegos \& Jordan unpubl.).

\section{Boundary conditions and forcing functions}

For easy experimentation with the model we parameterized the concentrations of $N_{0}$, and $C_{0}$, and $I(t)$ and $T(t)$ [forcing functions for in situ irradiance, $I(t)$, and water temperature, $T(t)]$ as simple functions of time. Data in Jordan et al. (1991a) indicate that the weekly averaged concentration of nitrate at the mouth of the Rhode River declines from a peak of about $40 \mu \mathrm{M}$ in early spring to near detection limits in summer. For the spring decline we chose an empirical function having a sigmoidal approach to 0 :

$$
N_{0}=\frac{N_{0}^{\max }}{2}\left[1-\tanh \left(\frac{t-t_{\mathrm{m}}}{t_{\mathrm{d}}}\right)\right]
$$

where $N_{0}{ }^{\max }(\mu \mathrm{M})$ is the maximal $N$ concentration at the seaward boundary, $t_{\mathrm{m}}$, the inflection day, is the day at which $N_{0}=N_{0}{ }^{\max } / 2$, and $t_{\mathrm{d}}$ controls the rate of decline.

Boundary chlorophyll, $C_{0}$, and the forcing functions for in situ irradiance, $I(t)$, and water temperature, $T(t)$, were represented by smoothly varying polynomial fits to field data measured weekly. $C_{0}$ was fit to data measured during 1991, a year with chlorophyll concentrations similar to the long-term averaged data in Fig. 3 of Jordan et al. (1991a). Depth-averaged available irradiance was calculated from daily integrals of incident photon flux recorded at the Smithsonian pier adjacent to segment 4 and diffuse attenuation coefficients interpolated from weekly measurements. Concentration of dissolved phosphate at the boundary is much less variable seasonally than the concentrations in upstream segments. We used a constant value of $0.25 \mu \mathrm{M}$ for $P_{0}$. broadly consistent with previous measurements made in the Rhode River (Jordan et al. 1991a) and adjacent segments of Chesapeake Bay (Fisher et al. 1992, Malone et al. 1996).

$B_{0}{ }^{\mathrm{N}}$ and $B_{0}{ }^{\mathrm{P}}$ were allowed to vary stoichiometrically with $C_{0}$, but the possibility of 'luxury consumption' of nutrients means that concentrations of $Q_{0}{ }^{\mathrm{N}}$ and $Q_{0}{ }^{\mathrm{P}}$ may depart from strict stoichiometric ratios. As formulated here, the concentration of e.g. $Q_{0}{ }^{\mathrm{N}}$ may vary between 0 (internal stores empty) and $Q_{N}{ }^{\max } B_{0}{ }^{N}$ (internal stores full), and similarly for $Q_{0}{ }^{\mathrm{P}}$. We represented the fraction of fullness of internally stored nutrients at the boundary by dimensionless parameters $f_{0}{ }^{\mathrm{QN}}$ and $f_{0}{ }^{Q P}$; that is, we set $Q_{0}{ }^{N}=f_{0}{ }^{Q N} Q_{N}{ }^{\text {max }} B_{0}{ }^{N}$, and similarly for $Q_{0}{ }^{p}$. For internally stored nitrogen at the boundary we calculated the fraction of capacity using the Michaelis-Menten factor, i.e. $f_{0}{ }^{\mathrm{N}}=N_{0} /\left(N_{0}+K_{\mathrm{S}}{ }^{\mathrm{N}}\right)$, to incorporate the observation (Fisher et al. 1992) that physiological indicators of $\mathrm{N}$ limitation parallel the seasonal depletion of DIN. We assigned a fixed value to $f_{0}{ }^{Q P}$ in keeping with the relative constancy of turnover times of DIP ( $<2$ h; Fisher et al. 1992), maintaining $f_{0}{ }^{Q P}$ constant within runs, but allowing it to vary between runs in the sensitivity analysis (see below). The model was implemented on a VAX minicomputer in FORTRAN77 using a fourth-order Runge-Kutta numerical solution with a $0.01 \mathrm{~d}$ time step. 
Table 2. Limits of the uniform distributions from which parameters were drawn in the Monte Carlo generalized sensitivity analysis, and source or rationale

\begin{tabular}{|c|c|c|c|}
\hline Parameter & $\begin{array}{l}\text { Lower } \\
\text { limit }\end{array}$ & $\begin{array}{l}\text { Upper } \\
\text { limit }\end{array}$ & Source or rationale \\
\hline$\theta_{\text {chl a }}$ & 0.25 & 1.25 & Implies C:chl $a$ of 20 to $100 \mathrm{mg} \mathrm{C}(\mathrm{mg} \mathrm{chl} \mathrm{a})^{-1}$ for a C: $N$ molar ratio of 6.6 \\
\hline$\theta_{N \cdot P}$ & 10 & 22 & Goldman (1980), range for high relative growth rate \\
\hline$Q_{N}{ }^{\max }$ & 0.5 & 2.5 & $\begin{array}{l}\text { Terry (1980) cited by Caperon (1982) showed cellular N:P ratio covaried with supply N:P } \\
\text { up to }-56\end{array}$ \\
\hline$Q_{p}^{\max }$ & 0.5 & 6.0 & Mackereth (1953) \\
\hline$f_{0}{ }^{\mathrm{QP}}$ & 0.1 & 1.0 & By definition, $K_{\mathrm{Q}}{ }^{\mathrm{P}} \leq f_{0}{ }^{\mathrm{QP}} \leq 1$ \\
\hline$K_{\mathrm{Q}}{ }^{\mathrm{N}}$ & 0.01 & 0.1 & $\begin{array}{l}\text { Riegman \& Mur (1984), stored limiting nutrient never exceeds more than a few percent } \\
\text { of functional nutrient }\end{array}$ \\
\hline$K_{\mathrm{Q}}{ }^{\mathrm{P}}$ & 0.01 & 0.1 & As for $K_{Q}^{N}$ \\
\hline$K_{\mathrm{S}}^{\mathrm{N}}$ & 0.1 & 5.0 & Eppley et al. (1969) \\
\hline$T_{\text {thr }}$ & 0 & 10 & Fig. 3 in Jordan et al. (1991a) \\
\hline$r_{r}^{\mathrm{P}}$ & 0.0 & 0.6 & Fig. 3 in Jordan et al. (1991a) \\
\hline$N_{0}^{\max }$ & 30 & 90 & $\begin{array}{l}\text { Minimum is approximate } \mathrm{NO}_{3} \text { concentration of local runoff; maximum is intermediate } \\
\text { between upper and middle Chesapeake Bay in spring (Malone et al. 1996) }\end{array}$ \\
\hline$t_{\mathrm{m}}$ & 80 & 150 & Fig. 1, this study \\
\hline$t_{\mathrm{d}}$ & 5 & 30 & Fig. 1, this study \\
\hline$\theta_{\mathrm{N} . \mathrm{P}}^{\text {sed }}$ & 0 & 8 & Nixon et al. (1980) \\
\hline
\end{tabular}

Table 3. Algorithm for classifying behavior of simulations produced by Monte Carlo generalized sensitivity analysis. - criterion unspecified

\begin{tabular}{|c|c|c|c|c|}
\hline \multirow[t]{2}{*}{ Simulated result } & \multicolumn{4}{|c|}{ Behavior classification } \\
\hline & Extraordinary bloom & Average bloom & Insufficient $\mathrm{N}$ & Insufficient $\mathrm{P}$ \\
\hline Peak chl a $\left(\mathrm{mg} \mathrm{m}^{-3}\right)$ & $>120$ & 70 to 110 & $<60$ & $<60$ \\
\hline Date of peak chl a & Before 30 May & 31 Mar to 10 May & - & - \\
\hline Final chi $a\left(\mathrm{mg} \mathrm{m}^{-3}\right)$ & $<50$ & $<50$ & - & - \\
\hline Date of $\mathrm{N}$ depletion & - & After 20 Mar & Before $30 \mathrm{Apr}$ & After 30 May \\
\hline
\end{tabular}

\section{GENERALIZED SENSITIVITY ANALYSIS}

Generalized sensitivity analysis (Hornberger \& Spear 1981) is a procedure for analyzing the behavior of models of environmental processes when many of the important parameters have not yet been measured (e.g. the study is preliminary) or the necessary measurements are difficult to make. A Monte Carlo analysis is performed using a simulation model, drawing unknown parameters randomly from plausible distributions. The output of each model run is evaluated using an algorithm to determine whether it resembles behavior actually observed in the system. For a complete, general treatment of the procedure see Hornberger \& Spear (1981).

In our implementation of the procedure there were 14 parameters which were varied in the analysis. Parameters were drawn from uniform random distributions. The ranges and justifications are given in Table 2 . As noted above, several parameters were not varied among simulations in the analysis. These parameters are either well constrained by available information (e.g. maximal nutrient-saturated growth rate as a function of irradiance and temperature; Gallegos \& Jordon unpubl.), or vary on time scales too short to affect results on the seasonal time scale (e.g. $\rho_{N}{ }^{\max }, \rho_{p}{ }^{\max }$ ). Also held constant were the DIP concentration at the seaward boundary, initial conditions, and forcing functions describing chlorophyll concentration at the seaward boundary, irradiance, and water temperature. The time periods simulated began March 1 and ended June 30 , but output for time before March 20 was ignored to minimize dependence on initial conditions.

Simulated chlorophyll dynamics for each of 8000 model runs, with parameters drawn randomly from the distributions in Table 2, were classified by comparison with the criteria in Table 3 , chosen to represent the range of behavior observed in field. Simulations were classified as average blooms, extraordinary blooms, or 1 of 2 classes of bloom failures based on peak predicted chlorophyll concentrations, timing of the peak, final chlorophyll concentration and timing of DIN depletion 

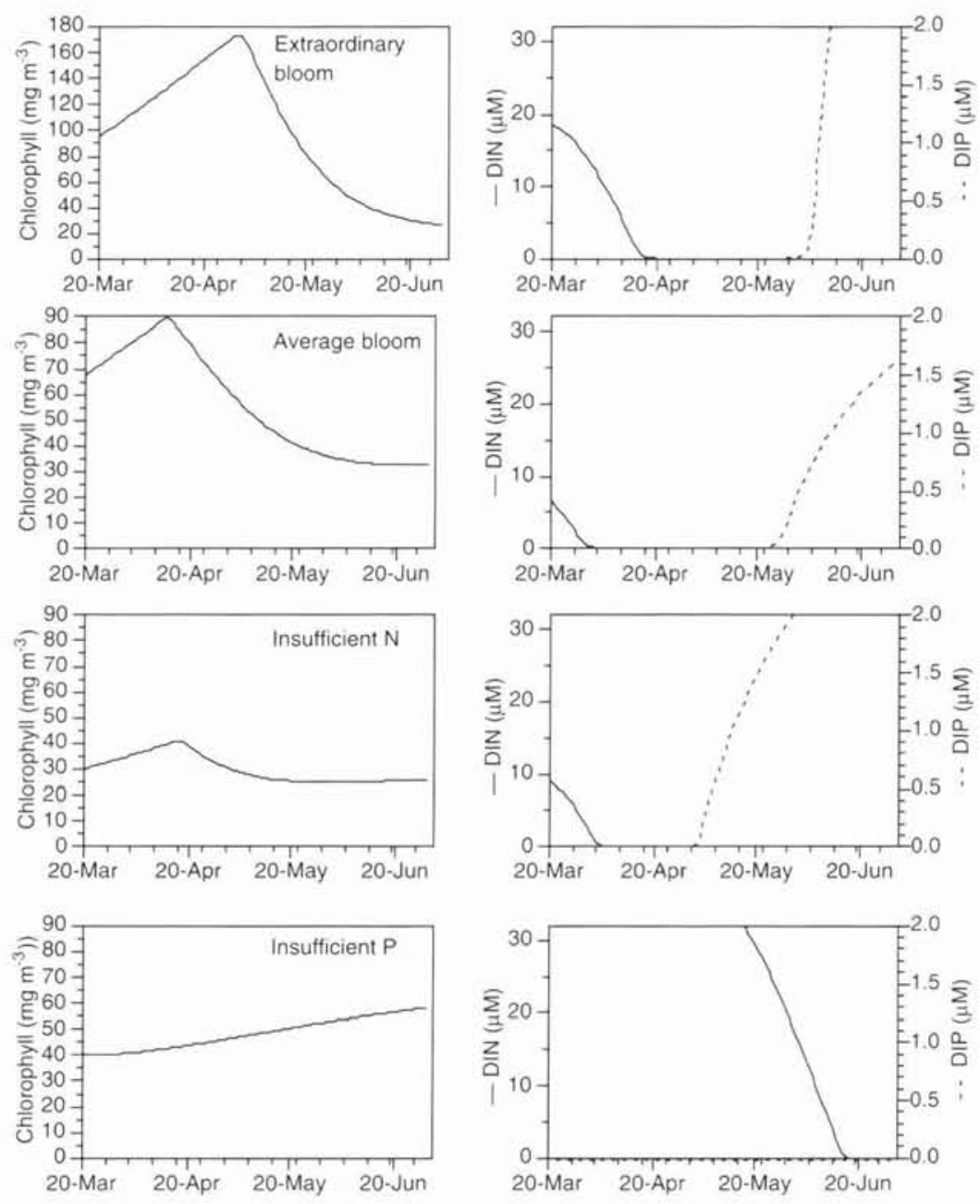

Fig. 2. Concentrations of (left panels) chlorophyll and (together on right panels) dissolved inorganic N (DIN) and dissolved inorganic P (DIP) as examples of different categories of blooms simulated by the model of light-, temperature-, and nutrient-dependent phytoplankton net growth in the Rhode River estuary. Classification criteria are given in Table 3 . Parameters producing the different classes of behavior are given in Table 4

(Table 3). We classified bloom failures as due to insufficient $\mathrm{P}$ if simulated DIN persisted beyond late May (as in 1988, 1993, 1994; cf. Fig. 1) or as due to insufficient $\mathrm{N}$ if DIN was depleted prior to late April (as in 1995).

We analyzed the parameter sets that produced the different classes of bloom and bloom failures using canonical discriminant analysis. We first performed a stepwise canonical discriminant analysis to identify a subset of model parameters that best distinguished among the classes of blooms. In this procedure, model parameters that have the least predictive power to discriminate amongst the categories of bloom and bloom failure are successively eliminated from the analysis. A backward elimination method was used, in which the initial analysis included all 14 parameters, and the parameter having the lowest partial $r^{2}$ was dropped from the succeeding analysis, until all remaining parameters had a partial $\mathrm{r}^{2}$ $\geq 0.05$. On this reduced parameter set we performed a full canonical discriminant analysis to determine the linear combination of the remaining model parameters that best distinguished the classes of simulated blooms or bloom failures. Only parameter sets producing some class of observed behavior were entered into the discriminant analysis.

\section{MODELING RESULTS}

Of the 8000 simulations, 153 produced output meeting the criteria for average bloom, 86 produced extraordinary blooms, 37 produced insufficient $\mathrm{P}$ bloom failures, and 619 produced insufficient $\mathrm{N}$ bloom failures. Most simulations (7105) did not meet the criteria for any of the behavior categories, due in part to our specification of non-overlapping criteria (e.g. for simulated peak chlorophyll; Table 3 ), or due to simulation of behavior not observed in the field data. Most instances of unclassified behaviors were due to simulation of $N$ depletion prior to 20 March or of final chlorophyll in excess of $50 \mathrm{mg} \mathrm{m}^{-3}$ (cf. Fig. 1, Table 3). The large number of simulations of unclassified behavior is not surprising considering the wide range from which parameters were drawn (Table 2) and restrictive definitions of behavioral categories (Table 3).

The simulated trajectories of chlorophyll, nitrogen, and phosphorus for representative members of each class, of course, vary much more smoothly than field data, but otherwise represent many features of the observations (Fig. 2). For example, in both the simulated and field data, DIN was depleted in years with blooms, but not in years with insufficient $\mathrm{P}$ to support a bloom (Figs. $1 \&$ 2). Some differences between simulated and observed trajectories may be due to our simplified representation of the system. For example, the simulated rise of chlorophyll in extraordinary blooms occurs more slowly than the actual rise, probably due to simulating the supply of boundary DIN as a sigmoidal decline, rather than as episodic pulses as in the real system (Jordan et al. 1991b, Gallegos et al. 1992). Also, the predicted time delay between the depletion 
Table 4. Parameter sets resulting in characteristic examples of the different classes of simulated blooms. Definitions and units of parameters are given in Table 1

\begin{tabular}{|c|c|c|c|c|}
\hline Parameter & Extraordinary bloom & Average bloom & Insufficient $\mathrm{N}$ & Insufficient $\mathrm{P}$ \\
\hline$\theta_{\mathrm{chl} \mathrm{d}}$ & 0.335 & 0.429 & 1.207 & 0.563 \\
\hline$\theta_{N . p}$ & 11.9 & 17.46 & 15.49 & 17.7 \\
\hline$Q_{N}^{\max }$ & 0.71 & 0.47 & 0.60 & 0.58 \\
\hline$Q_{p}^{\max }$ & 5.38 & 2.89 & 0.77 & 3.93 \\
\hline$f_{0} \mathrm{QP}^{\mathrm{P}}$ & 0.75 & 0.95 & 0.80 & 0.23 \\
\hline$K_{2}{ }^{N}$ & 0.04 & 0.065 & 0.019 & 0.03 \\
\hline$K_{Q}{ }^{p}$ & 0.022 & 0.063 & 0.047 & 0.070 \\
\hline$K_{\mathrm{S}} \mathrm{N}$ & 1.92 & 2.59 & 2.63 & 4.16 \\
\hline$T_{\text {thr }}$ & 1.85 & 6.4 & 1.24 & 9.18 \\
\hline$r_{t}^{\mathrm{P}}$ & 0.32 & 0.10 & 0.16 & 0.02 \\
\hline$N_{0} \max$ & 75.2 & 44.8 & 40.5 & 69.7 \\
\hline$t_{\mathrm{m}}$ & 116 (26 Apr) & 94 (4 Apr) & 95 (5 Apr) & 149 (29 May) \\
\hline$t_{\mathrm{d}}$ & 11 & 20 & 8 & 28 \\
\hline$\theta_{N}$ sed & 1.0 & 2.4 & 2.0 & 6.0 \\
\hline
\end{tabular}

of DIN and the commencement of DIP buildup has not been observed in the field.

Parameters giving rise to the representative simulated trajectories are given in Table 4. Interestingly, the simulated trajectories of nutrient concentrations are similar to one another in years classified as average bloom and as insufficient $\mathrm{N}$ (Fig. 2). In years with simulated average blooms, the flux of DIN across the seaward boundary and the flux of P from local sediment (Table 4 ) are sufficient to support bloom formation and draw the simulated $N$ concentration down to similar levels as in years classified insufficient $\mathrm{N}$.

In the stepwise canonical discriminant analysis, 7 parameters with little power to discriminate amongst the classes of behavior (i.e. those having partial $r^{2}<$ 0.05 ) were eliminated from the analysis, and 7 parameters were retained (Table 5 ). The first 3 parameters to be eliminated were related to cellular nutrient physiology: the half-saturation concentration for DIN uptake, $K_{\mathrm{S}}^{\mathrm{N}}$, and the relative half-saturation cell quotas for internally stored $\mathrm{N}$ and $\mathrm{P}, K_{\mathrm{Q}}{ }^{\mathrm{N}}$ and $K_{\mathrm{Q}}{ }^{\mathrm{P}}$. Also removed from the analysis were parameters governing the rate of decline (but not the inflection date) of DIN at the boundary $\left(t_{\mathrm{d}}\right)$, the threshold temperature for sediment nutrient release $\left(T_{\text {thr }}\right)$, the N:P ratio of sediment nutrient release $\left(\theta_{N: p^{\text {sed }}}\right)$, and lastly with a partial $r^{2}=0.041$, the maximal internal $N$ storage factor $\left(Q_{N}{ }^{\max }\right)$. These eliminated parameters were unimportant in determining the type of bloom simulated.

The parameters retained in the full canonical discriminant analysis were important in determining the type of bloom simulated. The standardized canonical coefficients (Table 5) quantify the contribution of each of the original model parameters (standardized to zero mean and unit variance) to the derived variables that best separate the classes of predicted bloom behavior. The parameters with the highest standardized weighting coefficients for the first canonical variate were the biomass $\mathrm{N}$ :chlorophyll ratio, $\theta_{\mathrm{chl} \text { a }}$ (negatively) and the maximal phosphorus release rate, $r_{t}^{\mathrm{p}}$ (positively) (Table 5). The rank order of the values for $\theta_{\text {chl a }}$ and $r_{r}^{p}$ in Table 4 is consistent with these relative weightings. That is, for the negatively weighted $\theta_{\mathrm{chl} a}$, the parameter values for the classes of bloom behavior are ranked

Table 5. Partial $\mathrm{r}^{2}$ calculated for parameters in stepwise canonical discriminant analysis, and standardized canonical coefficients of parameters retained in the full canonical discriminant analysis. Third canonical axis (not shown) provided no additional separation of behavior classes. Definitions and units of parameters are given in Table $1, \mathrm{n} / \mathrm{r}$ : not retained for the full canonical discriminant analysis

\begin{tabular}{|c|c|c|c|}
\hline Parameter & Partial $r^{2}$ & $\begin{array}{c}\text { First } \\
\text { canonical } \\
\text { coefficient }\end{array}$ & $\begin{array}{c}\text { Second } \\
\text { canonical } \\
\text { coefficient }\end{array}$ \\
\hline$\theta_{\text {chila }}$ & 0.565 & -1.425 & -0.078 \\
\hline$\theta_{N p}$ & 0.055 & 0.233 & -0.175 \\
\hline$Q_{N}^{\max }$ & 0.039 & $\mathrm{n} / \mathrm{r}$ & $\mathrm{n} / \mathrm{r}$ \\
\hline$Q_{p}^{\max }$ & 0.105 & 0.210 & -0.457 \\
\hline$f_{0}{ }^{\mathrm{QP}}$ & 0.079 & 0.332 & -0.101 \\
\hline$K_{\mathrm{Q}}^{\mathrm{N}}$ & $<0.001$ & $\mathrm{n} / \mathrm{r}$ & $\mathrm{n} / \mathrm{r}$ \\
\hline$K_{Q}{ }^{p}$ & 0.005 & $n / r$ & $\mathrm{n} / \mathrm{r}$ \\
\hline$K_{\mathrm{s}}{ }^{\mathrm{N}}$ & 0.002 & $\mathrm{n} / \mathrm{r}$ & $\mathrm{n} / \mathrm{r}$ \\
\hline$T_{\text {tht }}$ & 0.014 & $\mathrm{n} / \mathrm{r}$ & $\mathrm{n} / \mathrm{r}$ \\
\hline$r_{t}^{\mathrm{P}}$ & 0.315 & 0.915 & -0.509 \\
\hline$N_{0} \max$ & 0.241 & 0.608 & 0.338 \\
\hline$t_{\mathrm{m}}$ & 0.307 & 0.566 & 0.842 \\
\hline$t_{\mathrm{d}}$ & 0.024 & $\mathrm{n} / \mathrm{r}$ & $\mathrm{n} / \mathrm{r}$ \\
\hline$\theta_{N} p^{\text {sed }}$ & 0.019 & $\mathrm{n} / \mathrm{r}$ & $\mathrm{n} / \mathrm{r}$ \\
\hline
\end{tabular}




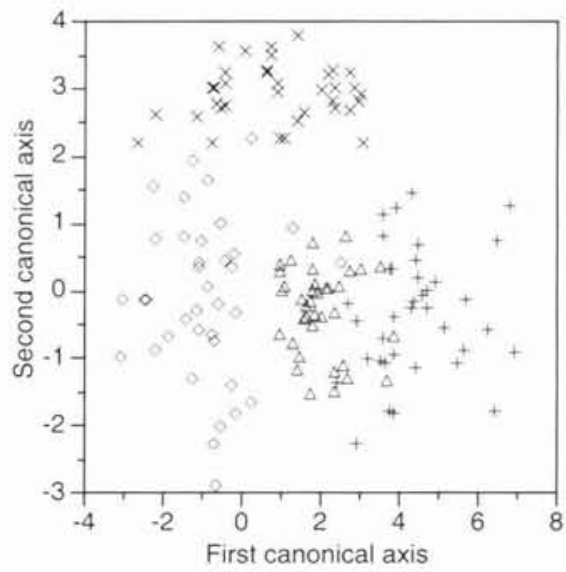

Fig. 3. Scatter diagram of scores on first and second canonical variable axes. First canonical variable separates $(0)$ insufficient $N,(\Delta)$ average bloom, and $(+)$ extraordinary bloom categories of behavior. Second canonical variable separates $(x)$ insufficient P from the other categories of behavior. For clarity, only the first 37 points (i.e. the number of occurrences of the rarest category) of each category are shown. Definitions and classification criteria for the categories of behavior are given in Table 3. Standardized coefficients of the canonical discriminant analysis are given in Table 5

in the order, extraordinary bloom < average bloom < insufficient $\mathrm{P}<$ insufficient $\mathrm{N}$. Similarly for the positively weighted parameter, $r_{r}^{P}$, the rank order in Table 4 is extraordinary bloom $>$ (average bloom $=$ insufficient $\mathrm{N}$ ) > insufficient $\mathrm{P}$. The maximal boundary DIN concentration, $N_{0}{ }^{\max }$, and the boundary DIN inflection date, $t_{m}$, were moderately weighted by the first canonical variate. Collectively these weightings suggest that bloom occurrence is sensitive to the supply of both $\mathrm{N}$ and $\mathrm{P}$, and that reduced nutrient supply can be partially compensated by reduced $\mathrm{N}$ to chlorophyll ratio. The first canonical variate separated (in order of decreasing score) the categories of extraordinary bloom, average bloom, and insufficient $\mathrm{N}$ (Fig. 3); but the category of insufficient $\mathrm{P}$ overlapped with both insufficient $\mathrm{N}$ and average bloom on the first canonical variate (Fig. 3).

The second canonical variate separated insufficient $\mathrm{P}$ from both insufficient $\mathrm{N}$ and from average bloom, thus completing the separation of categories not fully achieved by the first canonical variate (Fig. 3). The second canonical variable was most strongly influenced by the boundary DIN inflection date $\left(t_{\mathrm{m}}\right)$, and to a lesser extent by $r_{t}^{\mathrm{P}}$ and by the luxury $\mathrm{P}$ storage capacity, $\mathrm{Q}_{\mathrm{P}}{ }^{\max }$ (Table 5). The DIN inflection date was weighted positively, and the 2 parameters related to $\mathrm{P}$ supply were weighted negatively. Persistence of DIN into summer is the distinguishing feature of the insufficient $P$ category (Fig. 2), and it requires both sustained influx of DIN and low P influx to prevent utilization of the DIN in bloom formation. Due to the strong positive contribution of $t_{\mathrm{m}}$ and negative contributions of $r_{r}^{\mathrm{P}}$ and $Q_{p}{ }^{\max }$ to the second canonical variable, combinations of parameters that produce low peak chlorophyll and persistent DIN have high values on the second canonical variate.

\section{DISCUSSION}

\section{Interannual variability of observed spring blooms}

Peak springtime chlorophyll concentrations in segment 4 of the Rhode River varied widely from 1987 to 1995. Two years, 1990 and 1991 , had peak concentrations similar to the mean from 1978 to 1989 (cf. Jordan et al. 1991a), but overall variability was more than an order of magnitude (Fig. 1). Interannual variability is common in estuaries. Large differences in the timing and location of the winter/spring diatom bloom in the mainstem Chesapeake Bay may be due to competing effects of suspended particles and nutrients carried by freshwater runoff, which vary greatly from year to year (Harding 1994). In the Neuse River (North Carolina, USA) estuary, episodic phytoplankton blooms may result from pulsed inputs of nitrate by runoff events, which obscure seasonal patterns in nitrate concentrations, and account for higher annual primary production in wet years than in drier years (Mallin et al. 1993). Similarly, episodic freshwater flow triggers phytoplankton blooms in the Rhode River (Jordan et al. 1991b, Gallegos et al. 1992). Therefore, lack of a pronounced spring bloom in years with low Susquehanna River flow and early nitrate depletion (e.g. 1995; Fig. 1) is not surprising. More commonly, however, blooms failed to develop in years with high Susquehanna flow and persistent nitrate (e.g. 1988, 1993, 1994; Fig. 1). These observations emphasize the importance, in subestuaries, of the interaction between remote watershed processes that deliver excess nitrogen (Fisher et al. 1992) and local processes (presumably at the sediment-water interface) that make phosphorus available. The analysis of model parameters that generated the 2 types of bloom failure indicated that low sediment $\mathrm{P}$ release rates, together with persistent boundary DIN and low boundary input of internally stored $\mathrm{P}$, were associated with the mode of bloom failure more commonly observed in the field (Table 5).

We believe that the canonical discriminant analysis of the model parameters helps resolve the apparent conflict between our observations here that blooms fail to occur when nitrate is persistent and our previous observations that blooms are triggered by the arrival of nitrate (Jordan et al. 1991b, Gallegos et al. 1992). Whenever allochthonous P supply rates are low, phyto- 
plankton are unable to utilize the nitrate present and blooms fail to develop. When P supply rates are high, nitrate is depleted early, and if the initial nitrate supply was sufficient (and $\theta_{\mathrm{chl}}$ sufficiently low), then blooms of average magnitude develop. Episodic resupply of nitrate in such years leads to extraordinary blooms. Previous analyses that focused on correlates with bloom magnitude (Jordan et al. 1991b) or dynamics of extraordinary blooms (Gallegos et al. 1992) tended to ignore bloom failures that are indicative of the importance of P supply.

The role of $\mathrm{P}$ is also supported by experiments involving factorial additions of $\mathrm{N}$ and $\mathrm{P}$ that indicated occasional, weak stimulation of phytoplankton net growth rate in this system by $\mathrm{P}$ addition in the spring (Gallegos \& Jordan unpubl.). DIN concentrations are in excess at a time of year when temperatures are low and daylength is short, so that stimulation of net growth rate by addition of $\mathrm{P}$ was frequently indiscernible. Similarly, 'experimental' additions of $\mathrm{P}$ to the model indicated that $\mathrm{P}$ addition should stimulate phytoplankton growth rate in the spring by an amount $\left(\leq 0.25 \mathrm{~d}^{-1}\right)$ that would be difficult to detect in $1 \mathrm{~d}$ incubation experiments (Gallegos \& Jordan unpubl.). However, even undetectably small stimulations in growth due to $\mathrm{P}$ inputs can eventually lead to blooms. A Pstimulated net growth rate of only $0.1 \mathrm{~d}^{-1}$, if sustained for about $2 \mathrm{wk}$, can result in blooms of the magnitude observed (Fig. 2).

The cause of interannual differences in the timing and amount of nitrate input to the system is easily attributed to variations in riverine inputs (Malone et al. 1988, Harding 1994; also cf. Mallin et al. 1993). Factors that might cause interannual variations in sediment $\mathrm{P}$ release rates are less clear, but need to be elucidated for a more complete understanding of bloom formation. Temperature (Nixon et al. 1980) and dissolved oxygen (Callender 1982, Watanabe \& Tsunoga 1984), the most frequently cited covariates of sediment $\mathrm{P}$ release rates, do not appear to vary systematically in the Rhode River between bloom and non-bloom years (Gallegos unpubl.).

It is interesting that bloom failure due to insufficient $\mathrm{P}$ was the least frequently simulated condition when drawing environmental and physiological parameters randomly from plausible distributions (only 37 times in 8000 trials), but was one of the more frequently observed behaviors (i.e. 3 times in 8 years; Fig. 1). This observation suggests that persistent nitrate at the boundary and low rates of sediment P release, factors that contributed heavily to the second canonical variable (Table 5), may have a common causal factor. That is, persistent $\mathrm{NO}_{3}$ at the boundary and low sediment $\mathrm{P}$ release rates appear to occur together more frequently in the field than when selecting parameters for those processes randomly in the model. As discussed above, low sediment $\mathrm{P}$ release rates are a necessary condition for having persistent nitrate; but whether high nitrate and/or associated low salinity cause low $\mathrm{P}$ release rates is uncertain. The presence of sea salts may promote phosphate release by enhancing precipitation of iron sulfides in anaerobic sediments and thereby reducing the availability of iron oxyhydroxides that can immobilize phosphate (Caraco et al. 1990). However, it is not clear whether salinity fluctuations observed in the Rhode River are large enough or persistent enough to affect phosphate release via this mechanism.

\section{Reduced parameter set}

Of the parameters eliminated in the stepwise canonical discriminant analysis, $3\left(\theta_{\mathrm{N}: \mathrm{p}^{\text {sed }}}, T_{\mathrm{thr}}\right.$ and $\left.t_{\mathrm{d}}\right)$ were related to environmental controls on allochthonous nutrient fluxes, and $4\left(K_{\mathrm{s}}{ }^{\mathrm{N}}, K_{\mathrm{Q}}{ }^{\mathrm{N}}, K_{\mathrm{Q}}{ }^{\mathrm{P}}\right.$, and $\left.\mathrm{Q}_{\mathrm{N}}{ }^{\mathrm{max}}\right)$ were related to algal physiological responses and chemical composition. Although these parameters were not important in determining the dynamics of the spring bloom, they may be very important in other respects. The importance of a parameter is to a great degree constrained by the definition of the behavior of interest and by the structure of the model. For example, $\theta_{\mathrm{N}} \mathrm{p}^{\text {sed }}$ is the primary parameter controlling the midsummer chlorophyll concentration, which was not considered in this analysis, but was important to calibration of the model to a particular year (Gallegos \& Jordan unpubl.). Similarly, the parameters controlling the phytoplankton physiological response to nutrients are precisely those used in resource competition theory (Tillman 1977) and would be indispensable in any attempt to understand environmental controls on species composition of the blooms. Species composition of blooms has obvious water quality implications. For example, the collapse of a bloom of fast-sinking diatoms fuels deepwater oxygen depletion in estuaries (Malone et al. 1988), whereas other phytoplankton, such as the colonial prymnesiophyte Phaeocystis sp., may lyse before sinking, thereby fueling the microbial loop in surface waters (van Boekel et al. 1992). For the purpose of understanding the magnitude of the peak chlorophyll concentration in spring, however, the analysis suggests that attention should be directed at the processes represented by the parameters retained by the stepwise canonical discriminant analysis.

\section{Phytoplankton physiological parameters}

Three of the parameters retained by the stepwise canonical discriminant analysis, $\theta_{\text {chl } d,} Q_{\mathrm{P}}^{\max }$, and $\theta_{\mathrm{N} . \mathrm{P} \text {. }}$ 
relate to phytoplankton composition and physiology. $\theta_{\mathrm{N}: p}$ just barely exceeded the cutoff criterion and was not weighted strongly in either canonical variate (Table 5). $\theta_{\text {chl a }}$ was weighted most strongly by the analysis. Low values of $\theta_{\mathrm{chl} \text { a }}$ tend to score high on the first canonical axis because of the negative standardized canonical discriminant coefficient for $\theta_{\mathrm{chla}}$ for the first canonical variate (Table 5). High scores on the first canonical axis (low values of $\theta_{\text {chl al }}$ ) were associated with extraordinary blooms (Fig. 3). The mass balance calculations in the model are carried out in terms of concentrations of $\mathrm{N}$ and $\mathrm{P}$, and concentrations of biomass $\mathrm{N}$ are converted to units of phytoplankton chlorophyll by division by $\theta_{\mathrm{chl}}$. Thus it is not surprising that low values of $\theta_{\text {chl d }}$ would be associated with blooms of extraordinary magnitude.

Blooms in the Rhode River and other western shore, mesohaline tributaries of Chesapeake Bay are frequently dominated by dinoflagellates (Loftus et al. 1972, Tyler \& Seliger 1978, Gallegos 1992). The dinoflagellate Prorocentrum minimum sometimes forms dense blooms in late spring in the mesohaline regions of the Bay (Tyler \& Seliger 1978, Harding \& Coats 1988). Average $\theta_{\mathrm{chl} \text { a }}$ calculated from Harding \& Coats (1988, their Table 3 ) for populations of $P$. minimum from the surface mixed layer was $0.46 \mu \mathrm{M} \mathrm{N}(\mu \mathrm{g}$ chl $a)^{-1}$, similar to the value of 0.48 used in calibrating the model for the 'average bloom' year 1991 (Gallegos \& Jordan unpubl.). Interestingly, subsurface populations of Prorocentrum, which are believed to provide the seed stock for very dense blooms (Tyler \& Seliger 1978), had an average value of $0.33 \mu \mathrm{M} \mathrm{N}(\mu \mathrm{g} \mathrm{chl} a)^{-1}$ (Harding \& Coats 1988), which would score those populations high on the first canonical axis.

Our range for $\theta_{\mathrm{chl} \text { a }}$ used in the Monte Carlo simulations (Table 2) was wider than that inferred from culture data (Goldman 1980), but narrower than that estimated by Gowen et al. (1992) from the concentrations of chlorophyll and nitrate in Scottish sea lochs. Gowen et al. (1992) (who reported $\mathrm{chl} a \mathrm{~N}$ yield ratios, the reciprocal of our $\theta_{\text {chl d }}$ ) pointed out that the yield ratio realized in the field is an ecosystem property, depending on the partitioning of algal-assimilated $\mathrm{N}$ between algae, grazers, detritus, and (we would add) dissolved organic $\mathrm{N}$. While they considered culture data to indicate a lower limit of $\theta_{\mathrm{chl}}$ a they recommended using their even lower ecosystem minimum for estimating a possible worst case response of coastal systems to increased anthropogenic $\mathrm{N}$ loading. Our results confirm that values of $\theta_{\mathrm{chl} \text { a }}$ typifying pure phytoplankton cultures are appropriate predictors of the ecosystem response to $\mathrm{N}$ loading when $\mathrm{N}$ loading leads to blooms. This works because blooms are times when most of the available $\mathrm{N}$ is sequestered in the phytoplankton. Nevertheless, low values of $\theta_{\text {chl a }}$ may still typify the chem- ical composition of the phytoplankton even when blooms are prevented by environmental (e.g. sediment $\mathrm{P}$ release rate) or physiological (e.g. P storage capacity) parameters.

The other parameter of physiological significance retained by the stepwise discriminant analysis was that governing the phytoplankton internal storage capacity of $P, Q_{p}{ }^{\max }$, which was weighted moderately by canonical variable 1 , and moderately negatively by the second canonical variate (Table 5). Nielsen (1996) and Nielsen \& Tonseth (1991) speculated that high storage capacity for $\mathrm{P}$ was an important factor enabling Gymnodinium galatheanum and Gyrodinium aureolum, respectively, to form dense blooms. In our implementation of the model, $Q_{p}{ }^{\max }$ primarily acts multiplicatively with $f_{0}{ }^{\mathrm{QP}}$ as an input of $\mathrm{P}$ at the seaward boundary at a time when $\mathrm{P}$ is limiting to phytoplankton growth (Gallegos \& Jordan unpubl.), which suggests that internally stored P entering at the seaward boundary is moderately important as a source of $\mathrm{P}$ for average and extraordinary blooms, and that insufficient $\mathrm{P}$ is associated with an absence of stored P (Fig. 3). In the model, the internal pool of the limiting nutrient is never more than a few percent of the biomass pool of that nutrient (Riegman \& Mur 1984). Therefore, when $\mathrm{NO}_{3}$ is persistent at the boundary, $\mathrm{P}$ should be limiting to phytoplankton there (Fisher et al. 1992, Malone et al. 1996), and internally stored P entering at the boundary would be insufficient to promote a bloom. However, when $\mathrm{N}$ is in short supply, $\mathrm{Q}_{\mathrm{p}}^{\max }$ could become important in controlling $\mathrm{P}$ storage for blooms triggered by pulsed delivery of DIN which can occur after DIN depletion (Jordan et al. 1991b, Gallegos et al. 1992).

\section{Management implications}

One of the principal deleterious effects of eutrophication in Chesapeake Bay has been the catastrophic reduction of seagrass habitat (Orth \& Moore 1984). Dennison et al. (1993) determined by correspondence analysis that seagrass survival to $1 \mathrm{~m}$ depth requires chl $a \leq 15 \mathrm{mg} \mathrm{m}^{-3}$ and suspended solids $\leq 15 \mathrm{~g} \mathrm{~m}^{-3}$. Using optical modeling and the seagrass light requirements estimated by Dennison et al. (1993), Gallegos (1994) determined that survival to a depth of $2 \mathrm{~m}$ would require growing season median chl $a \leq 10 \mathrm{mg}$ $\mathrm{m}^{-3}$ and suspended solids $<5 \mathrm{~g} \mathrm{~m}^{-3}$. Much of the habitat deemed suitable for restoration of seagrass to depths of 1 or $2 \mathrm{~m}$ occurs along the highly articulated shorelines of subestuaries such as the Rhode River (Batiuk et al. 1992). Therefore, understanding the controls of chl $a$ in shallow waters is important to restoring seagrass habitats. 
The categories of behavior generated by the model, which ranged from bloom failure to blooms of extraordinary magnitude (Fig. 2), all utilized the same chlorophyll concentration at the seaward boundary, representing the main stem of Chesapeake Bay. Phytoplankton blooms that place seagrass beds under stress, therefore, can occur in subestuaries without concomitant blooms in the main stem. The fact that the category of bloom failure most frequently observed in the field was insufficient $\mathrm{P}$ indicates that reduction of locally regenerated phosphorus is sufficient to prevent spring blooms of average or extraordinary magnitude in the Rhode River. However, chlorophyll concentrations categorized as bloom failures in this system (Table 3 ) still exceeded the $15 \mathrm{mg} \mathrm{m}^{-3}$ criterion for seagrasses. Indeed, even at the seaward boundary, chlorophyll concentration exceeded $15 \mathrm{mg} \mathrm{m}^{-3}$ for most, and $10 \mathrm{mg} \mathrm{m}^{-3}$ for all of the growing season. $\mathrm{Chl}$ a concentrations cannot be lower in the subestuary than at the seaward boundary, unless chl $a$ is removed, for example, by filter feeders (Cloern 1982). Therefore, reduction of $\mathrm{chl} \mathrm{a}$ concentrations in the main stem of the Bay as well as in the subestuaries would be required to restore seagrass habitat in the subestuaries. However, chl a concentrations within the subestuaries are usually much higher than in the main stem. Strategies to restore seagrasses in subestuaries will need to consider the interactions of $\mathrm{N}$ and $\mathrm{P}$ limitation that occur there.

Acknowledgements. This research was supported by the Smithsonian Environmental Sciences program. We thank J. Miklas, S. Hedrick, and N. Kobayashi for collection of field samples and laboratory analyses.

\section{LITERATURE CITED}

APHA (American Public Health Association) (1989) Standard methods for the examination of water and wastewater. APHA, Washington, DC

Batiuk RA, Orth RJ, Moore KA, Dennison WC, Stevenson JC, Staver L, Carter V, Rybicki N, Hickman RE, Kollar S, Bieber S, Heasly P, Bergstrom P (1992) Chesapeake Bay submerged aquatic vegetation habitat requirements and restoration goals: a technical synthesis. US EPA, Chesapeake Bay Program, Annapolis, MD

Callender E (1982) Benthic phosphorus regeneration in the Potomac River Estuary. Hydrobiologia 92:431-446

Caperon J (1982) Some interactions of biogeochemical cycles in the marine environment. In: Freney JR, Galbally IE (eds) Cycling of carbon, nitrogen, sulfur and phosphorus in terrestrial and aquatic ecosystems. Springer-Verlag. New York, p 143-150

Caraco N, Cole J, Likens GE (1990) A comparison of phosphorus immobilization in sediments of freshwater and coastal marine systems. Biogeochemistry 9:277-290

Cloern JE (1982) Does the benthos control phytoplankton biomass in South San Francisco Bay? Mar Ecol Prog Ser 9: 191-202
D'Elia CF, Sanders JG, Boynton WR (1986) Nutrient enrichment studies in a coastal plain estuary: phytoplankton growth in large-scale, continuous cultures. Can J Fish Aquat Sci 43:397-406

Dennison WC, Orth RJ, Moore KA, Stevenson JC, Carter V, Kollar S, Bergstrom PW, Batiuk RA (1993) Assessing water quality with submersed aquatic vegetation. BioSci 43 : $86-94$

Eppley RW, Rogers JN, McCarthy JJ (1969) Half-saturation constants for uptake of nitrate and ammonium by marine phytoplankton. Limnol Oceanogr 14:912-920

Fisher TR, Peele ER, Ammerman JW, Harding LW Jr (1992) Nutrient limitation of phytoplankton in Chesapeake Bay. Mar Ecol Prog Ser 82:51-63

Gallegos CL (1992) Photosynthesis, productivity, and species composition in a eutrophic sub-estuary: comparison of bloom and non-bloom assemblages. Mar Ecol Prog Ser 81: $257-267$

Gallegos CL (1994) Refining habitat requirements of submersed aquatic vegetation: role of optical models. Estuaries 17:198-219

Gallegos CL, Jordan TE, Correll DL (1992) Event-scale response of phytoplankton to watershed inputs in a subestuary: timing, magnitude, and location of phytoplankton blooms. Limnol Oceanogr 37:813-828

Goldman JC (1980) Physiological processes, nutrient availability, and the concept of relative growth rate in marine phytoplankton ecology. In: Falkowski PG (ed) Primary productivity in the sea. Plenum Press, New York, p 179-193

Gowen RJ, Tett P, Jones KJ (1992) Predicting marine eutrophication: the yield of chlorophyll from nitrogen in Scottish coastal waters. Mar Ecol Prog Ser 85:153-161

Harding LW Jr (1994) Long-term trends in the distribution of phytoplankton in Chesapeake Bay: roles of light, nutrients and streamflow. Mar Ecol Prog Ser 104:267-291

Harding LW Jr, Coats DW (1988) Photosynthetic physiology of the dinoflagellate, Prorocentrum mariae-lebouriae, during its subpycnocline transport in Chesapeake Bay. J Phycol $24: 77-89$

Hornberger GM, Spear RC (1981) An approach to the preliminary analysis of environmental systems. J Environ Manage 12:7-18

Jeffrey SW, Humphrey GF (1975) New spectrophotometric equations for determining chlorophyll $a, b, c 1$, and $c 2$ in higher plants, algae and natural phytoplankton. Biochem Physiol Pfl 167:191-194

Jordan TE, Correll DL, Miklas J, Weller DE (1991a) Nutrients and chlorophyll at the interface of a watershed and an estuary. Limnol Oceanogr 36:251-267

Jordan TE, Correll DL, Miklas J, Weller DE (1991b) Longterm trends in estuarine nutrients and chlorophyll, and short-term effects of variation in watershed discharge. Mar Ecol Prog Ser 75:121-132

Legendre L (1990) The significance of microalgal blooms for fisheries and for the export of particulate organic carbon in oceans. J Plankton Res 12:681-699

Loftus ME, Subba Rao DV, Seliger HH (1972) Growth and dissipation of phytoplankton in Chesapeake Bay. I. Response to a large pulse of rainfall. Chesapeake Sci 13:282-299

Mackereth FJ (1953) Phosphorus utilization by Asterionella formosa Hass, J Exp Bot 4:296-313

Mallin MA, Paerl HW, Rudek J, Bates PW (1993) Regulation of estuarine primary production by rainfall and river flow. Mar Ecol Prog Ser 93:199-203

Malone TC, Conley DJ, Fisher TR, Glibert PM, Harding LW Jr, Sellner KG (1996) Scales of nutrient-limited phyto- 
plankton productivity in Chesapeake Bay. Estuaries 19: 371-385

Malone TC, Crocker LH, Pike SE, Wendler BW (1988) Influences of river flow on the dynamics of phytoplankton production in a partially stratified estuary. Mar Ecol Prog Ser 48:235-249

Nielsen MV (1996) Growth and chemical composition of the toxic dinoflagellate Gymnodinium galatheanum in relation to irradiance, temperature and salinity. Mar Ecol Prog Ser 136:205-211

Nielsen MV, Tonseth CP (1991) Temperature and salinity effect on growth and chemical composition of Gyrodinium aureolum Hulburt in culture. J Plankton Res 13:389-398

Nixon SW (1987) Chesapeake Bay nutrient budgets-a reassessment. Biogeochemistry 4:77-90

Nixon SW, Kelly JR, Furnas BN, Oviatt CA, Hale SS (1980) Phosphorus regeneration and the metabolism of coastal marine bottom communities. In: Tenore KR, Coull BC (eds) Marine benthic dynamics. University of South Carolina, Columbia, p 219-242

Orth RJ, Moore KA (1984) Distribution and abundance of submerged aquatic vegetation in Chesapeake Bay: an historical perspective. Estuaries 7:531-540

Paasche E. Erga SR (1988) Phosphorus and nitrogen limitation of phytoplankton in the inner Oslofjord (Norway). Sarsia 73:229-243

Parsons TR, Takahashi M, Hargrave B (1984) Biological oceanographic processes. Pergamon, New York

Pennock JR, Sharp JH (1994) Temporal alternation between light- and nutrient-limitation of phytoplankton production in a coastal plain estuary. Mar Ecol Prog Ser 111:275-288

Riegman R, Mur LR (1984) Theoretical considerations on

This article was submitted to the editor growth kinetics and physiological adaptation of nutrientlimited phytoplankton. Arch Microbiol 140:96-100

Rudek J, Paerl HW, Mallin MA, Bates PW (1991) Seasonal and hydrological control of phytoplankton nutrient limitation in the lower Neuse River Estuary, North Carolina. Mar Ecol Prog Ser 75:133-142

Sakshaug E, Olsen Y (1986) Nutrient status of phytoplankton blooms in Norwegian waters and algal strategies for nutrient competition. Can J Fish Aquat Sci 43:389-396

Shoaf WT, Lium BW (1976) Improved extraction of chlorophyll $a$ and $b$ from algae using dimethyl sulfoxide. Limnol Oceanogr 21:926-928

Smith SV (1984) Phosphorus versus nitrogen limitation in the marine environment. Limnol Oceanogr 29:1149-1160

Strickland JDH, Parsons TR (1972) A practical handbook of seawater analysis. Fisheries Research Board of Canada, Ottawa

Terry KL (1980) Nitrogen and phosphorus requirements of Pavlova lutheri in continuous culture. Bot Mar 23:757-764

Tillman D (1977) Resource competition between planktonic algae: an experimental and theoretical approach. Ecology $58: 338-348$

Tyler MA, Seliger HH (1978) Annual subsurface transport of a red tide dinoflagellate to its bloom area: water circulation patterns and organism distributions in the Chesapeake Bay. Limnol Oceanogr 23:227-246

van Boekel WHM, Hansen FC, Riegman R, Bak RPM (1992) Lysis-induced decline of a Phaeocystis spring bloom and coupling with the microbial foodweb. Mar Ecol Prog Ser 81:269-276

Watanabe Y, Tsunoga S (1984) Adsorption-desorption control of phosphate in anoxic sediment of a coastal sea, Funka Bay, Japan. Mar Chem 15:71-83

Manuscript received: December 9, 1996

Revised version accepted: June 2, 1997 